\title{
Training the Next Generation of Researchers in the Science and Application of Atmospheric Rivers
}

Anna M. Wilson, William Chapman, Ashley Payne, Alexandre M. Ramos, Christoph Boehm, Diego Campos, Jason Cordeira, Rene Garreaud, Irina V. Gorodetskaya, Jonathan J. Rutz, Carolina Viceto, and F. Martin Ralph

\section{Atmospheric Rivers Colloquium Summer School}

What: The Colloquium Summer School aimed to provide the next generation of atmospheric scientists with an in-depth look at the cutting edge techniques in understanding, monitoring, and predicting atmospheric rivers and their associated high-impact weather.

When: 24 June- 5 July 2019

Where: La Jolla, California

AFFILIATIONS: Wilson, Chapman, and Ralph-Center for Western Weather and Water Extremes, Scripps Institution of Oceanography, University of California, San Diego, La Jolla, California; Payne-Department of Climate and Space Sciences and Engineering, University of Michigan, Ann Arbor, Michigan; Ramos_-Instituto Dom Luiz, Faculdade de Ciências, Universidade de Lisboa, Lisbon, Portugal; BoehmUniversity of Cologne, Cologne, Germany; Campos-Universidad de Chile, and Direccion Meteorologica de Chile, Santiago, Chile; Cordeira_-Plymouth State University, Plymouth, New Hampshire; GarreaudUniversidad de Chile, Santiago, Chile; Gorodetskaya and Viceto-Centre for Environmental and Marine Studies, Department of Physics, University of Aveiro, Aveiro, Portugal; Rutz-NWS Western Region, Salt Lake City, Utah 
B eginning with research in the 1990s, atmospheric rivers (ARs) have been identified as a significant mechanism of heat and moisture transport across the globe, typically poleward. ARs can trigger precipitation extremes, flooding, and strong winds during landfall on the western coasts of the continents, along with providing essential water supplies (Newell et al. 1992; Zhu and Newell 1998; Ralph et al. 2004; Dettinger et al. 2011; Lavers et al. 2011; Lavers and Villarini 2013; Gorodetskaya et al. 2014; Paltan et al. 2017; Waliser and Guan 2017; Ramos et al. 2018; Nash et al. 2018; Neff 2018; Viale et al. 2018; among many others). They are defined as long, narrow, transient corridors of strong horizontal water vapor transport, and are typically associated with low-level jets and extratropical cyclones (Ralph et al. 2018).

A wide variety of disciplines have come together to study ARs and their impacts, including hydrologists, atmospheric scientists, engineers, chemists, and others. The Center for Western Weather and Water Extremes (CW3E) at the University of California, San Diego's Scripps Institution of Oceanography has become a hub for these activities. CW3E hosted the first two International Atmospheric Rivers Conferences (IARC) in 2016 (Ralph et al. 2017) and 2018 (Ramos et al. 2019), and in late June and early July of 2019, hosted the Atmospheric River Colloquium Summer School, ${ }^{1}$ which is described in this meeting summary.

\section{Colloquium overview}

The 2019 Atmospheric River Colloquium Summer School (http://cw3e.ucsd.edu/ar_colloquium_2019/) took place in early summer in the Martin Johnson House at the Scripps Institution of Oceanography in La Jolla, California. It was hosted and sponsored by CW3E. The steering committee that organized the Colloquium Summer School was composed of an international group of instructors and student representatives (Fig. 1).

Goals. The main goal of the AR Colloquium Summer School was to provide the next generation of atmospheric scientists an improved understanding of 1) the fundamental dynamics and physics associated with ARs, including their role in the water cycle and impacts in different regions across the globe; 2 ) the techniques to detect, observe, model, and forecast ARs at all relevant time scales, including in future climate scenarios; and 3) applications of AR science to water management, engineering, and hazard resilience.

To achieve this goal, the Colloquium Summer School aimed to bring together a diverse group of international students, at different stages in their education (from a recent high school graduate to post-docs) and with experience in varying disciplines relevant to ARs, to learn from an international group of experts. The Colloquium agenda was designed to allow students to interact with these leaders in AR science, gaining hands-on experience as well as participating in specially crafted lecture sessions.

Lectures. The steering committee communicated with students who attended the 2nd IARC and the Student Forecasting Workshop that followed (Ramos et al. 2019) for their input on the program. The structure and content of the Colloquium was also loosely based on the book Atmospheric Rivers, which is authored by a large group of international experts on various aspects of atmospheric river science (Ralph et al. 2019). Atmospheric Rivers provides a comprehensive overview of AR science including the relevant atmospheric processes, observational systems, global and regional perspectives, hydrology, and applications

Following this template, the Colloquium featured a large group of international lecturers, many of whom are coauthors of the book. F. Martin Ralph, chief editor of the AR book and director of CW3E, provided an introduction, featuring key results

${ }^{1}$ Costs for the Colloquium, including logistics and participant travel, were provided by CW3E primarily using support from a major program focused on exploring the potential for better atmospheric river forecasts to enable additional flexibility in reservoir operations in the western United States. This Forecast-Informed Reservoir Operations (FIRO) program (Jasperse et al. 2015; http://cw3e.ucsd.edu/FIRO/) is led by the U.S. Army Corps of Engineers' Engineer Research and Development Center (ERDC). 


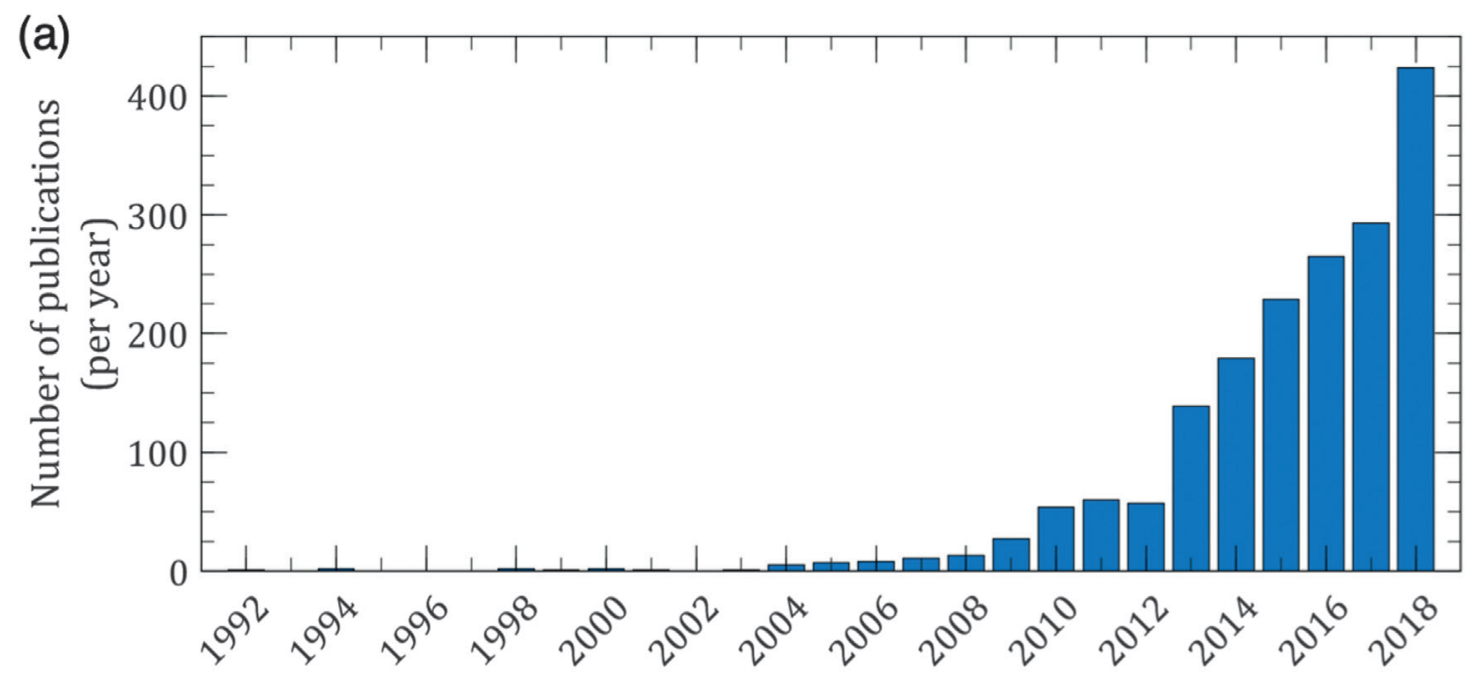

(b)
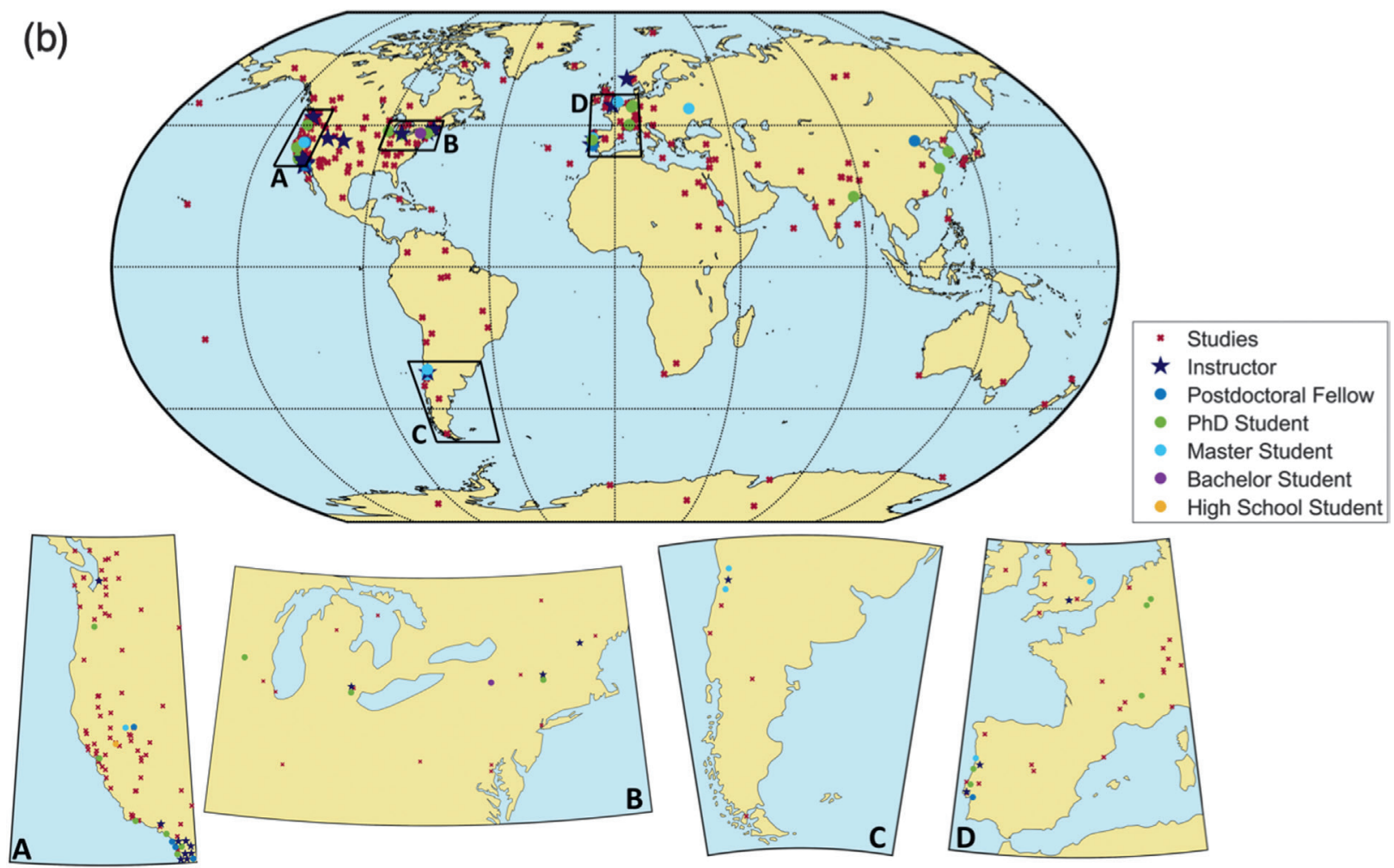

Fig. 1. (a) Peer review journal articles referring to the topic of ARs published per year. Papers were counted via Google Scholar. (b) Locations of Colloquium Summer School participants by education level, instructors, and study areas of ARs from (a).

that have emerged throughout the history of AR science and also on AR Recon and Observations. Ashley Payne and Jonathan Rutz then discussed the various algorithmic methods used to identify and track ARs, as well as efforts to quantify the uncertainty in AR climatology and impacts that arises from the use of these different approaches. Lance Bosart and Jay Cordeira described the atmospheric dynamics associated with ARs, including the physical mechanisms contributing to AR genesis, maintenance, and decay. Following an overview of the distribution of ARs globally, several lecturers highlighted AR science over regions of personal expertise, including Rene Garreaud (Chile), David Lavers (Great Britain), Alexandre Ramos (the Iberian Peninsula and South Africa), and Jonathan Rutz (western United States). 
Continuing with regional insights, Irina Gorodetskaya and Bill Neff shared their expertise on ARs that impact polar regions. In addition, Sasha Gershunov, among others, talked about past and present climate AR related research. Mike Dettinger, David Lavers, and Rene Garreaud described hydrologic processes that occur as AR-related precipitation interacts with the landscape in different regions of the globe while Larry Schick, Andrew Martin and Jeanine Jones focused on the short-term forecast of ARs and precipitation and its application for operations (e.g., the management of dams) and engineering. On the other hand, Duane Waliser described the subseasonal-to-seasonal predictability associated with ARs, and also spoke about projected long-term changes in AR climatology. Finally, Hans Christian Steen Larsen and Sarah Aarons shared knowledge on AR isotopes, Lagrangian analysis, aerosols and chemistry. The full agenda and instructors for each topic are listed on the Colloquium web page (https://cw3e.ucsd.edu/ar_colloquium_2019/).

Projects. In addition to lectures, students participating in the Colloquium had the opportunity to work on group projects in collaboration with other students and instructors. The purpose of these student projects was to develop a set of hypotheses motivated by outstanding questions in the scientific literature and to explore these hypotheses (as much as possible given the limited timeframe) using concrete case studies and statistical analysis (the datasets and cases were both provided by project supervisors and identified by students). Students discussed approaches they would use in an ideal setting and considered the scientific merit if the project were a success.

Both instructors and students were asked to contribute short project proposals before the start of the Colloquium. Given these prompts, students signed up for one or several project proposals of their interest and by the end of the first day of the Colloquium several projects were selected forming groups of 3-5 students. Student groups were encouraged to reach out to faculty in attendance who helped out as project supervisors, strengthening interaction among students and instructors and learning from each other. Structured project workspace was provided at the end of each lecture day and data and computational resources were made available. The eight student groups presented their work on the last day of the Colloquium.

Student projects included influences of ARs on precipitation and feedbacks at high latitudes, their response to changes in the position of tropical convective activity connected to ENSO variability, the role of the resolution and existence of topography over the western United States on AR-associated precipitation patterns, exploration of the Maya Express on flooding over the central United States and AR variability along the Chilean coastline.

Field outings. Along with lectures and project workspace, the Colloquium featured several planned field outings and social events. The social events provided an opportunity for students to get to know each other better outside of the classroom setting. The field activities gave students insight into applications-based science and data collection, encouraging them to think about the public utility of the scientific advances they will pursue. During the first event, students visited the National Oceanic and Atmospheric Administration's National Weather Service Weather Forecast Office in San Diego. They were able to interact with forecasters and learn how the output from global numerical weather prediction models is combined with output from higher resolution regional models and the expert knowledge of meteorologists to create forecasts, and then how these forecasts are communicated to the public in real time. The guided, highly interactive tour emphasized the importance of atmospheric science and demystified the creation of weather forecasts. Students were also able to learn and ask questions about the career trajectory of a National Weather Service employee.

Following this tour, students traveled to Scripps Institution of Oceanography, and along with instructors, received a tour of the Scripps pier, and were then able to participate in a 
radiosonde launch. This exercise was designed to bolster students' understanding of one of the data collection methodologies fundamental to modern weather prediction. The opportunity to experience real-world data gathering and field measurement methodology provided participants with insight into the rigors that precede the data analysis, assimilation, and advances in the understanding of atmospheric physical and dynamical processes.

\section{Outcomes}

The growth in research and applications associated with atmospheric rivers over the last decade has included several events that in combination have forged an international community of scientists, engineers and many others. These have included two International Atmospheric River Conferences, with a third planned for October 2020 in Santiago, Chile; creation of a book on ARs; creation of the Atmospheric River Tracking Method Intercomparison Project; many sessions at major conferences; field experiments, etc. The AR Colloquium represents an important extension of this community building focused on transfer of knowledge between scientists across various stages of their careers, ranging from early career new scientists to emeritus, with an emphasis on training for graduate students.

Attendees discussed future research directions and potential avenues for research collaboration. ARs were found to bridge separate yet related fields of study, including meteorology, hydrology, and sociology, which encouraged future cross-disciplinary research and collaboration. The student-led projects sparked enthusiasm for continued research, expanded skill sets, and inspired future applications. In particular, there was a focus on the diagnosis of Southern Hemisphere AR dynamics and impacts, since there has been much less investment in AR research in this region relative to other areas of the globe affected by these phenomena. Multiple student-driven projects are planned to be continued for future research and application in graduate work or summer projects. These include conditional forecast verification of model skill, mesoscale frontal waves and associated impacts, successive AR events, and South American climatological studies of vertical AR structure and impacts.

This Colloquium represents a new chapter in the emerging topic of atmospheric rivers as a key component of the global water cycle and source of extreme weather and water events in many parts of the world. With growing vulnerabilities of socioeconomic systems and ecosystems due to population growth and changing climate conditions, it is possible that additional training and knowledge transfer opportunities of this type will be needed on this topic. If so, the 2019 AR Colloquium provides a template for future summer schools focused on ARs, which would also benefit from lessons learned via feedback that was collected from participants.

Acknowledgments. The AR Colloquium Summer School 2019 Organizing Committee acknowledges the University of California, San Diego's Scripps Institution of Oceanography's Center for Western Weather and Water Extremes for support, as well as the proactive group of graduate students and postdoctoral scholars who provided invaluable logistical support throughout the conference. This publication and work were supported by U.S. Army Corps of Engineers Forecast Informed Reservoir Operations Grant W912HZ-15-2-0019. A. M. Ramos was supported by the Scientific Employment Stimulus 2017 from FCT (CEECIND/00027/2017). 


\section{References}

Dettinger, M. D., F. M. Ralph, T. Das, P. J. Neiman, and D. R. Cayan, 2011: Atmospheric rivers, floods and the water resources of California. Water, 3, 445-478, https://doi.org/10.3390/w3020445.

Gorodetskaya, I. V., M. Tsukernik, K. Claes, M. F. Ralph, W. D. Neff, and N. P. M. Van Lipzig, 2014: The role of atmospheric rivers in anomalous snow accumulation in East Antarctica. Geophys. Res. Lett., 41, 6199-6206, https://doi. org/10.1002/2014GL060881.

Jasperse, J., and Coauthors, 2015: A comprehensive plan to evaluate the viability of forecast informed reservoir operations for Lake Mendocino. Sonoma County Water Agency Rep., 374 pp.

Lavers, D. A., and G. Villarini, 2013: The nexus between atmospheric rivers and extreme precipitation across Europe. Geophys. Res. Lett., 40, 3259-3264, https:// doi.org/10.1002/grl.50636.

_ _ R. P. Allan, E. F. Wood, G. Villarini, D. J. Brayshaw, and A. J. Wade, 2011:Winter floods in Britain are connected to atmospheric rivers. Geophys. Res. Lett., 38, L23803, https://doi.org/10.1029/2011GL049783.

Nash, D., D. Waliser, B. Guan, H. Ye, and F. M. Ralph, 2018: The role of atmospheric rivers in extratropical and polar hydroclimate. J. Geophys. Res. Atmos., 123, 6804-6821, https://doi.org/10.1029/2017JD028130.

Neff, W., 2018: Atmospheric rivers melt Greenland. Nat. Climate Change, 8, 857858, https://doi.org/10.1038/s41558-018-0297-4.

Newell, R. E., N. E. Newell, Y. Zhu, and C. Scott, 1992: Tropospheric rivers? - A pilot study. Geophys. Res. Lett., 19, 2401-2404, https://doi.org/10.1029/92GL02916.

Paltan, H., D. Waliser, W. H. Lim, B. Guan, D. Yamazaki, R. Pant, and S. Dadson, 2017: Global floods and water availability driven by atmospheric rivers. Geophys. Res. Lett., 44, 10387-10395, https://doi.org/10.1002/2017GL074882.

Ralph, F. M., P. J. Neiman, and G. A. Wick, 2004: Satellite and CALJET aircraft observations of atmospheric rivers over the eastern North Pacific Ocean during the winter of 1997/98. Mon. Wea. Rev., 132, 1721-1745, https://doi. org/10.1175/1520-0493(2004)132<1721:SACA00>2.0.C0;2.
applications focus. Bull. Amer. Meteor. Soc., 98, 1969-1973, https://doi. org/10.1175/BAMS-D-16-0262.1.

_ M. M. Dettinger, M. M. Cairns, T. J. Galarneau, and J. Eylander, 2018: Defining "atmospheric river": How the Glossary of Meteorology helped resolve a debate. Bull. Amer. Meteor. Soc., 99, 837-839, https://doi.org/10.1175/BAMSD-17-0157.1.

, _ J. J. Rutz, and D. E. Waliser, 2019: Atmospheric Rivers. Springer, 366 pp., https://doi.org/10.1007/978-3-030-28906-5 .

Ramos, A. M., R. C. Blamey, I. Algarra, R. Nieto, L. Gimeno, R. Tomé, C. J. Reason, and R. M. Trigo, 2018: From Amazonia to southern Africa: Atmospheric moisture transport through low-level jets and atmospheric rivers. Ann. N. Y. Acad. Sci., 1436, 217-230, https://doi.org/10.1111/nyas.13960.

_ Multi-disciplinary studies and high-impact applications of atmospheric rivers. Atmos. Sci. Lett., 20, e935, https://doi.org/10.1002/asl.935.

Viale, M., R. Valenzuela, R. D. Garreaud, and F. M. Ralph, 2018: Impacts of atmospheric rivers on precipitation in southern South America. J. Hydrometeor., 19, 1671-1687, https://doi.org/10.1175/JHM-D-18-0006.1.

Waliser, D., and B. Guan, 2017: Extreme winds and precipitation during landfall of atmospheric rivers. Nat. Geosci., 10, 179-183, https://doi.org/10.1038/ ngeo2894.

Zhu, Y., and R. E. Newell, 1998: A proposed algorithm for moisture fluxes from atmospheric rivers. Mon. Wea. Rev., 126, 725-735, https://doi.org/10.1175/15200493(1998)126<0725:APAFMF>2.0.C0;2. 